\title{
Comparison of the Antibacterial Activity of the Ethanol Extract vs Hydroalcoholic Extract of the Leaves of Mangifera indica L. (Mango) in Different Concentrations: An In Vitro Study
}

\author{
Victoria Cardenas ${ }^{1}$, Román Mendoza ${ }^{2}$, Lucy Chiong ${ }^{3}$, Elca del Aguila ${ }^{4}$, Daniel Alvítez-Temoche ${ }^{5}$, Frank Mayta-Tovalino ${ }^{6}$
}

\begin{abstract}
Aim: To compare the in vitro antibacterial activity of different types of hydroalcoholic extracts of the leaves of the Mangifera indica L. (mango) plant on the strain of Staphylococcus aureus ATCC $6538^{\text {TM. }}$.

Materials and methods: This study was experimental in vitro and determined the antibacterial activity of four dilutions: Mangifera indica L. ethanol extract (MEE) and Mangifera indica L. hydroalcoholic extract (MHE) at 50\% and 100\% on cultures of S. aureus ATCC $6538^{\text {Th }}$ comparing with the positive control (chlorhexidine $0.12 \%$ ) and negative (alcohol $96^{\circ}$ ) in Mueller Hinton agar cultures using the Kirby-Bauer diffusion method for each study group and incubating the cultures at $37^{\circ} \mathrm{C}$ for 24 hours.

Results: It was found that the $50 \%$ and $100 \%$ MEE had a smaller size of the inhibitory halo of $21.3 \pm 0.5$ and $24.1 \pm 0.8 \mathrm{~mm}$, respectively. In addition, with respect to the $50 \%$ and $100 \% \mathrm{MHE}$, it was found that they had a higher antibacterial activity of $24.6 \pm 0.5$ and $33.5 \pm 1.2 \mathrm{~mm}$, respectively. Conclusion: Mango leaf extracts are potent antibacterial, proving 100\% MHE to be more effective, thus confirming the presence of active constituents in medicinal plants.

Clinical significance: This research has a great clinical applicability due to the opening of research lines that prove the usefulness of these extracts in the therapeutic control of certain oral diseases.

Keywords: Antibacterial activity, Ethanol extract, Hydroalcoholic extract, Mangifera indica L.

The Journal of Contemporary Dental Practice (2020): 10.5005/jp-journals-10024-2763
\end{abstract}

\section{INTRODUCTION}

Bacterial resistance is a public health problem that involves the world's population. This is because bacteria that cause infectious diseases become resistant to antibiotics, so science has been in a position to take measures such as the development of new antibacterial that can cope with these multidrug-resistant bacteria. On the other hand, traditional medicine and phytotherapy has been gaining increasing strength since a wide variety of plants show that they have biological properties for the different conditions that man presents, so there is a great empirical source of active ingredients, it is convenient to clarify those properties. ${ }^{1-4}$

Currently, bacterial resistance against antibiotics has been increasing, resulting in a worldwide concern since mild infections cannot be controlled. This caused by the inappropriate and excessive use of drugs in addition to deficiencies in the prevention and control of infections. Since it is not possible to use first-line antibiotics, it is necessary to use more expensive medicines, which increases the costs for the family and society. ${ }^{5-8}$

In health sciences, for example, the use of antibiotics is justified in the presence of odontogenic infections and as prophylaxis in at-risk patients. Among stomatological infections, bacteremia and osteomyelitis are common as a result of invasive dental procedures whose multifactorial origin includes a very varied microflora, finding opportunistic microorganisms such as S. aureus, which is related to the onset of these diseases. ${ }^{79,10}$

In recent years, research shows various medicinal plants of stomatological interest, including Mangifera indica L., to
1Postgraduate Department, Doctoral Program in Dentistry, Faculty of Dentistry, Universidad Nacional Federico Villarreal, Lima, Peru

${ }^{2-4}$ Academic Department, Faculty of Dentistry, Universidad Nacional Federico Villarreal, Lima, Peru

${ }^{5}$ Academic Department, Faculty of Dentistry, Universidad Mayor de San Marcos, Lima, Peru

${ }^{6}$ Academic Department, Faculty of Dentistry, Universidad Nacional Federico Villarreal, Lima, Peru; Postgraduate Department, Faculty of Health Sciences, Universidad Científica del Sur, Lima, Peru

Corresponding Author: Frank Mayta-Tovalino, Academic Department, Faculty of Dentistry, Universidad Nacional Federico Villarreal, Lima, Peru; Postgraduate Department, Faculty of Health Sciences, Universidad Científica del Sur, Lima, Peru, Phone: +51 1 214-2500, e-mail: fmaytat@ucientifica.edu.pe

How to cite this article: Cardenas V, Mendoza R, Chiong L, et al. Comparison of the Antibacterial Activity of the Ethanol Extract vs Hydroalcoholic Extract of the Leaves of Mangifera indica L. (Mango) in Different Concentrations: An In Vitro Study. J Contemp Dent Pract 2020;21(2):202-206.

Source of support: Nil

Conflict of interest: None

which antibacterial properties are attributed due to its active substance that is mangiferin. As the phenolic compound is one of the most abundant chemical components in this plant, it is considered that it gives it the ability to inhibit or block the growth of certain microorganisms. Some bacteria that cause

() The Author(s). 2020 Open Access This article is distributed under the terms of the Creative Commons Attribution 4.0 International License (https://creativecommons. org/licenses/by-nc/4.0/), which permits unrestricted use, distribution, and non-commercial reproduction in any medium, provided you give appropriate credit to the original author(s) and the source, provide a link to the Creative Commons license, and indicate if changes were made. The Creative Commons Public Domain Dedication waiver (http://creativecommons.org/publicdomain/zero/1.0/) applies to the data made available in this article, unless otherwise stated. 
oral diseases such as S. mutans, E. faecalis, C. albicans, S. aureus and $E$. coli among others that have proven to be susceptible to Mangifera indica L. $^{11-15}$ In addition, according to the literature, the leaves of this plant have certain antibacterial properties due to the presence of saponins, steroids, alkaloids, anthracenocides, coumarins, flavonones, among other chemical compounds that are considered responsible for providing antimicrobial properties to this natural resource. ${ }^{4,11}$

Therefore, the main objective of this research was to compare the in vitro antibacterial effect of two types of extracts (ethanol and hydroalcoholic) based on the Mangifera indica L. (mango) leaf of Northern Peru against strains of Staphylococcus aureus ATCC $6538^{\mathrm{TM}}$ so that it can provide scientific evidence to the profile of this plant and incorporate it as a possible source of antibacterial agent.

\section{Materials and Methods}

The study was experimental in vitro, the execution of the present investigation was carried out in the Pharmaceutical Production Center (CENPROFARMA), in the Microbiology Laboratory of the Faculty of Pharmacy and Biochemistry of the National University of San Marcos (UNMSM). The sample was obtained using the means comparison formula with the Stata ${ }^{\circledR} 12.0$ software with a $95 \%$ confidence level, with a statistical power of 0.80 from the results of the pilot test, determining a sample size of $n=48$ discs embedded with the experimental substances in each of the six groups which was made up of $n=8$ discs.

Group I: 50\% MEE facing S. aureus

Group II: 100\% MEE facing S. aureus

Group III: 50\% MHE facing S. aureus

Group IV: $100 \%$ MHE facing S. aureus

Group V: chlorhexidine $0.12 \%$ vs $S$. aureus as a positive control Group VI: alcohol $96 \%$ facing S. aureus as a negative control

\section{Collection of Mangifera indica L. (Mango)}

The collection of mango leaves was made in the hamlet "Encuentros de Romero," on the banks of the Quiroz River, located in the province of Sullana, in the Department of Piura in Northern Peru. The hamlet is approximately 250 m.a.s.l. and $62 \mathrm{~km}$ from the district of "Lancones" that is between $80^{\circ} 28^{\prime \prime} 40^{\prime \prime}$ Longitude West and $4^{\circ} 40^{\prime \prime} 50^{\prime \prime}$ Latitude South (Regional Government of Piura, 2007). The average annual temperature for this area was

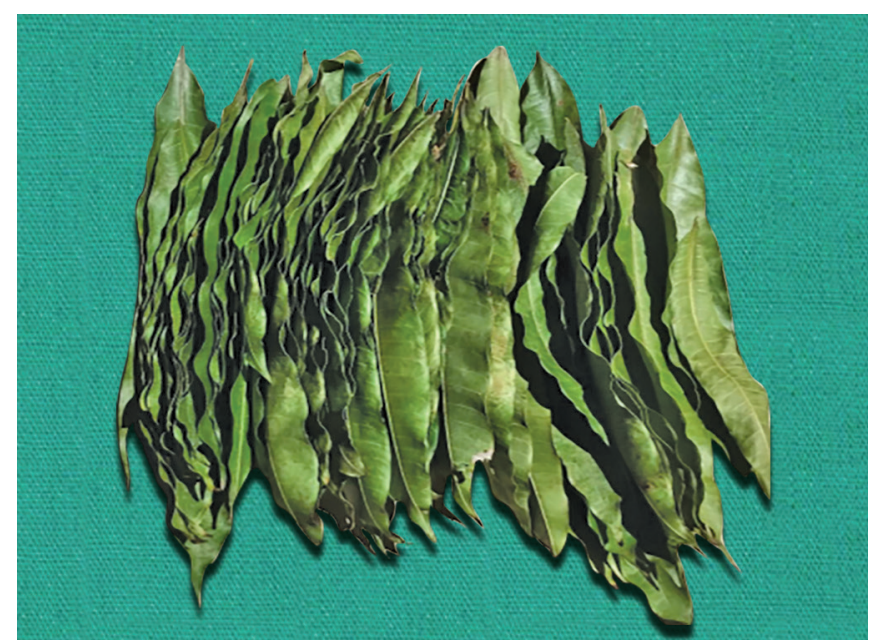

Fig. 1: Leaves of Mangifera indica L. $23^{\circ} \mathrm{C}$ and the temperature reaches its maximum end in the months of November and December $\left(34.2^{\circ} \mathrm{C}\right)$ and its minimum end in June $\left(15^{\circ} \mathrm{C}\right)$ (Fig. 1).

\section{Preparation of the Extracts and Taxonomic Classification}

A sample of mango leaves was taken to the Natural History Museum of the UNMSM for taxonomic determination, which certified the authenticity of the plant under study (Constancy No. 302-USM2018). Determining the following classification:

Division: Magnoliophyta

Class: Magnoliopsida

Subclass: Rosidae

Order: Sapindales

Family: Anacardiaceae

Genus: Mangifera

Species: Mangifera indica L.

In this investigation, the Mangifera indica L. leaves of the same species were used in all the tests performed, however, different preparations were made of the same plant (ethanol and hydroalcoholic extract). Subsequently, the leaves were washed with distilled water and allowed to dry at room temperature for a period of 5 days, then the physical chemical stabilization of the plant was started by putting it to dry 3 days in the oven at $40^{\circ} \mathrm{C}$. The leaves were crumbled and passed through a manual mill where it was pulverized for the preparation of the extracts (ethanolic and hydroalcoholic), $400 \mathrm{~mL}$ of the solvent was used for every $50 \mathrm{~g}$ of the dried plant, all this was stored in an amber bottle and it was macerated during 15 minutes movements once a day for 10 days. After maceration, it was filtered with a vacuum pump with no. 40 Whatman filter paper and the extract was poured into a glass source for further drying and taken to an incubation oven at $40^{\circ} \mathrm{C}$ for 4 days. Then, it was poured into a vial using $2 \mathrm{~g}$ in $4 \mathrm{~mL}$ of solvent. Finally, the same protocol was performed for both solvents.

\section{In Vitro Antimicrobial Susceptibility Testing}

The strain of S. aureus ATCC 6538 was obtained from the Gen Lab laboratory of Peru SAC and refrigerated between $4^{\circ} \mathrm{C}$ and $8^{\circ} \mathrm{C}$ on a plate with TSA agar, for the activation of the strain a colony with the bacteriological handle was taken and seeded in a tube with sterile TSB broth, then it was taken to the incubator at $37^{\circ} \mathrm{C}$ for 24 hours where turbidity showed growth of the suspension. The TSB broth was seeded on a plate with TSA agar and taken back to the incubator at $37^{\circ} \mathrm{C}$ for 24 hours. For the preparation of the inoculum, a certain amount of colonies was taken from pure colonies of the S. aureus microorganism and diluted in a test tube containing $10 \mathrm{~mL}$ of sterile physiological serum $(0.9 \%$ sodium chloride) such that the resulting solution had a turbidity corresponding to tube no. 1 of the MacFarland scale (turbidimetric scale consisting of a series of tubes with increasing turbidity that allows to find the approximate concentration of a bacterial solution) which corresponds to a concentration of $3 \times 10^{8} \mathrm{CFU} / \mathrm{mL}$. From this last solution a dilution of 1 in 3 was made, for this of this prepared solution $3 \mathrm{~mL}$ was taken and diluted to a total volume of $9 \mathrm{~mL}$ with physiological serum in a tube with sterile screw cap, the resulting solution had a concentration of $1 \times 10^{8} \mathrm{CFU} / \mathrm{mL}$. For inoculation of the plates, $100 \mu \mathrm{L}$ of the prepared bacterial inoculum $\left(1 \times 10^{8} \mathrm{CFU} / \mathrm{mL}\right)$ was added to 12 plates with Mueller Hinton agar and with the help of a Drigalski spatula the inoculum was spread throughout the plate in such a way that it was obtained a homogeneous growth, for which 
the handle slid in the plate in parallel and well compact covering the entire surface of the plate then the procedure was repeated rotating the plate $60^{\circ}$ in two more opportunities.

\section{Measurement of Inhibition Halos}

After 24 hours of incubation each plate was examined, the diameters of the entire inhibition zone were measured in millimeters passing through the center of each well. The measurement was performed in triplicate for each well with a Caliper Model: DC-515 digital vernier that measures up to one hundredth of a millimeter (Kirby-Bauer technique). Triplicate measurement values were averaged and rounded to report as a natural number (Fig. 2).

\section{Statistical Analysis}

A database was created in Excel 2010 and for the statistical analysis the statistical program Stata ${ }^{\circledR} 15.1$ was used. Descriptive analysis: the measures of central tendency (arithmetic mean) and dispersion (standard deviation, minimum and maximum) were calculated to describe the behavior of the dependent variable studied and double entry tables and bar graphs were drawn up with their lines of error. Inferential analysis: the hypothesis test and the Student's $t$ parametric tests were used for the comparison between two groups. The $F$ test through the variance analysis technique (ANOVA) was used to compare the four extracts. The level of significance that was used was 0.05 with a $95 \%$ confidence level.
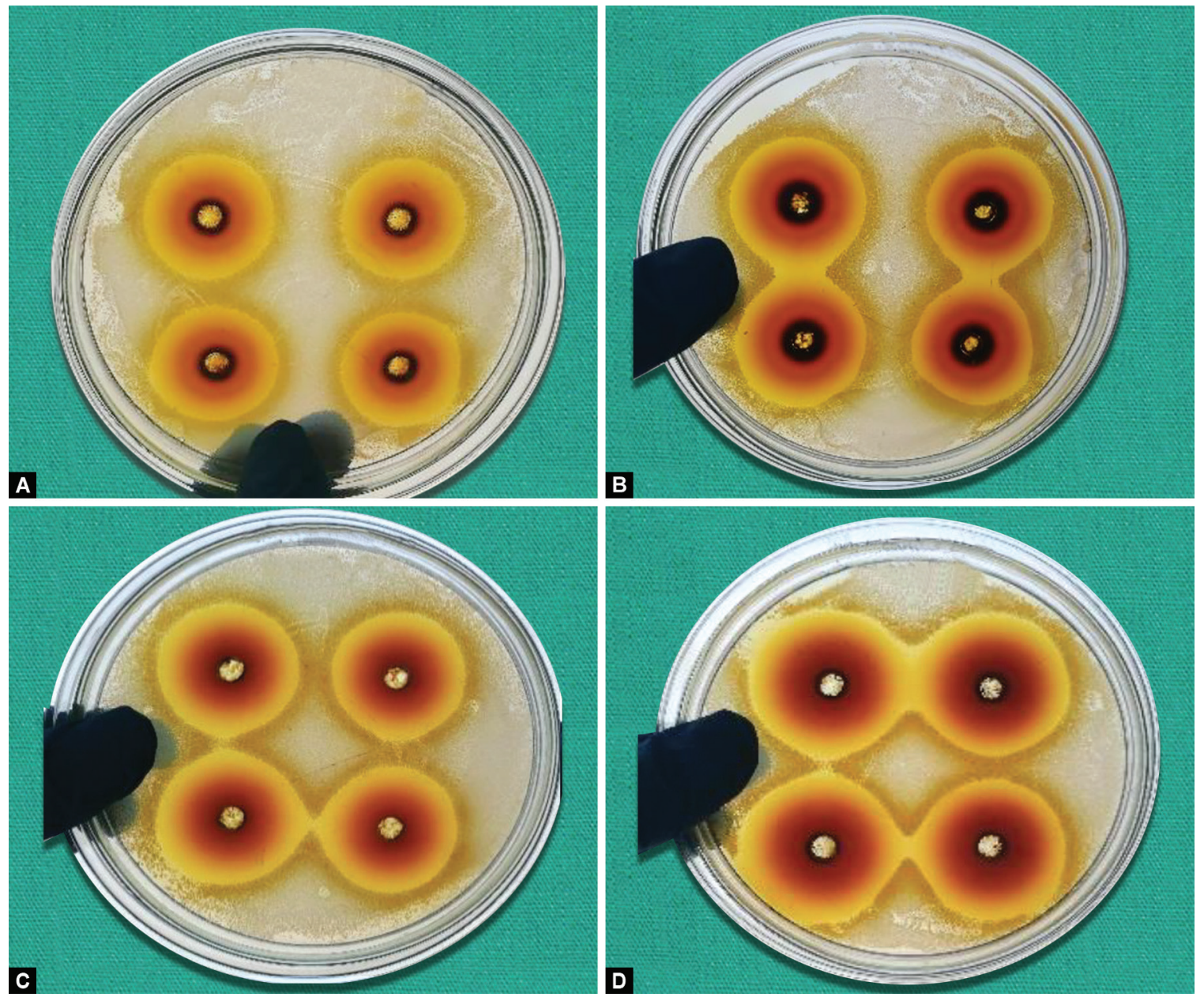

Figs 2A to D: Antibacterial activity: (A) Mangifera indica L. ethanol extract (MEE) 50\%; (B) MEE 100\%; (C) Mangifera indica L. hydroalcoholic extract (MHE) 50\%; (D) MHE 100\% 
Table 1: Comparison of the antimicrobial activity of Mangifera indica L.

\begin{tabular}{|c|c|c|c|c|c|c|c|}
\hline \multirow[b]{2}{*}{ Groups } & \multicolumn{4}{|c|}{24 hours } & \multirow[b]{2}{*}{$p^{*}$} & \multirow[b]{2}{*}{$p^{* *}$} & \multirow[b]{2}{*}{$p^{* * * *}$} \\
\hline & Mean & $S D$ & Min. & Max. & & & \\
\hline MEE $50 \%$ & 21.3 & 0.5 & 21.0 & 22.0 & $>0.05$ & 0.001 & $<0.001$ \\
\hline MEE 100\% & 24.1 & 0.8 & 23.0 & 25.0 & & & \\
\hline MHE 50\% & 24.6 & 0.5 & 24.0 & 25.0 & $>0.05$ & 0.001 & \\
\hline MHE 100\% & 33.5 & 1.2 & 32.0 & 35.0 & & & \\
\hline $\begin{array}{l}\text { Clorhexidine } \\
0.12 \%\end{array}$ & 25.3 & 1.5 & 24.0 & 27.0 & $>0.05$ & 0.001 & \\
\hline Alcohol $96^{\circ}$ & 6.0 & 0.0 & 6.0 & 6.0 & & & \\
\hline
\end{tabular}

All values were recorded in $\mathrm{mm}$

*Shapiro-Wilk test

**Student $t$ test

***ANOVA test

Level of significance $(p<0.05)$

MEE, Mangifera indica L. ethanolic extract; MHE, Mangifera indica L. hydroalcoholic extract

\section{Discussion}

Biofilm is a layer of homologous extracellular polysaccharides produced by some strains of $S$. aureus. This extracellular network serves as an aid for the adhesion of the bacterial community to different surfaces. It is also involved in the persistence and colonization of this bacterium in probes, prostheses and catheters. This biofilm can prolong the time of colonization and infection, as well as the dispersion to different parts of the human body. ${ }^{4,5,7}$ Infections develop from the deepening of this bacterium by a solution of tissue continuity due to trauma, skin or surgical lesions. These infections generate purulent material forming abscesses and can cause minor infections of the skin and soft tissues and invasive infections such as: infections of the central nervous system, respiratory, gastrointestinal and urinary tract, bacteraemia and osteomyelitis. ${ }^{16-20}$

In the present investigation the antibacterial activity of different mango leaf extracts on S. aureus strain ATCC 6538 was evaluated, the ethanolic and hydroalcoholic extracts were used at $50 \%$ and $100 \%$ dilutions on bacterial cultures, using the diffusion method from Kirby-Bauer wells and it was found that in effect the four dilutions have extremely sensitive activity, there are significant differences between them and in comparison with the positive control (chlorhexidine $0.12 \%$ ). The results obtained in this research agree with similar studies carried out by other authors.
For example, in the study conducted by Madduluri et al. ${ }^{21}$ the antibacterial activity of the leaves of five native plants was determined, including Mangifera indica L., comparing the effects of methanol and ethanol extracts and using the diffusion agar disk method in five different strains, including S. aureus. It was found that the five strains showed sensitivity to the extracts of the five plants being one of the most susceptible $S$. aureus with halos of $11.5 \mathrm{~mm}$ for the ethanolic extract and $15 \mathrm{~mm}$ for the methanolic extract of Mangifera indica L. concluding an antibacterial activity positive of the mango leaves coinciding with the present study. However, smaller halos were obtained here and a concentration of $10 \mathrm{mg} / \mathrm{mL}$ was used with native leaves of India while in the present study concentrations of $50 \%$ and $100 \%$ were used with native leaves of Peru. Similarly, Diso et al. ${ }^{22}$ evaluated the antibacterial activity of leaves and bark of mango tree native to Nigeria with aqueous extracts and chloroform using the diffusion method on methicillin-resistant S. aureus and verified that the extracts possess antimicrobial activity since they formed inhibition halos between $11 \mathrm{~mm}$ and $17 \mathrm{~mm}$ around the wells at $120 \mathrm{mg} / \mathrm{mL}$ which classifies this activity as very sensitive coinciding with the present work since that a positive antibacterial activity was found, although concentrations of $50 \%$ and $100 \%$ were used in the present study and the inhibition halos were between $21.38 \mathrm{~mm}$ and $33.5 \mathrm{~mm}$, these results suggest a sensitivity of these microorganisms to the evaluated plant. And further Diso et al. used a strain resistant to methicillin. Another study that found similar results was that described by Anand et al. ${ }^{23}$ who made an ethanolic extract of walnut and mango leaves at $20 \mathrm{mg} / \mathrm{mL}$ in India and applied it on oral bacterial strains including S. aureus with the diffusion method, which showed inhibition halos with an average of $14.67 \mathrm{~mm}$ that according to the Duraffourd scale, the bacterium is very sensitive to the antibacterial applied, thus verifying the effectiveness of the extract, possibly being attributed to the presence of bioactive compounds. This is consistent with the present study since it also used ethanol as a solvent although finding halos larger than 21.38 $\mathrm{mm}$ and $24.13 \mathrm{~mm}$ at $50 \%$ and $100 \%$, respectively being interpreted as highly sensitive. All these results are consistent with those described in the present study since we also found an antibacterial activity of the mango based ethanol and hydroalcoholic extract.

Within the main limitations of this research, we have found that when performing two types of extracts and several concentrations, the demand for supplies and reagents was extremely considerable,

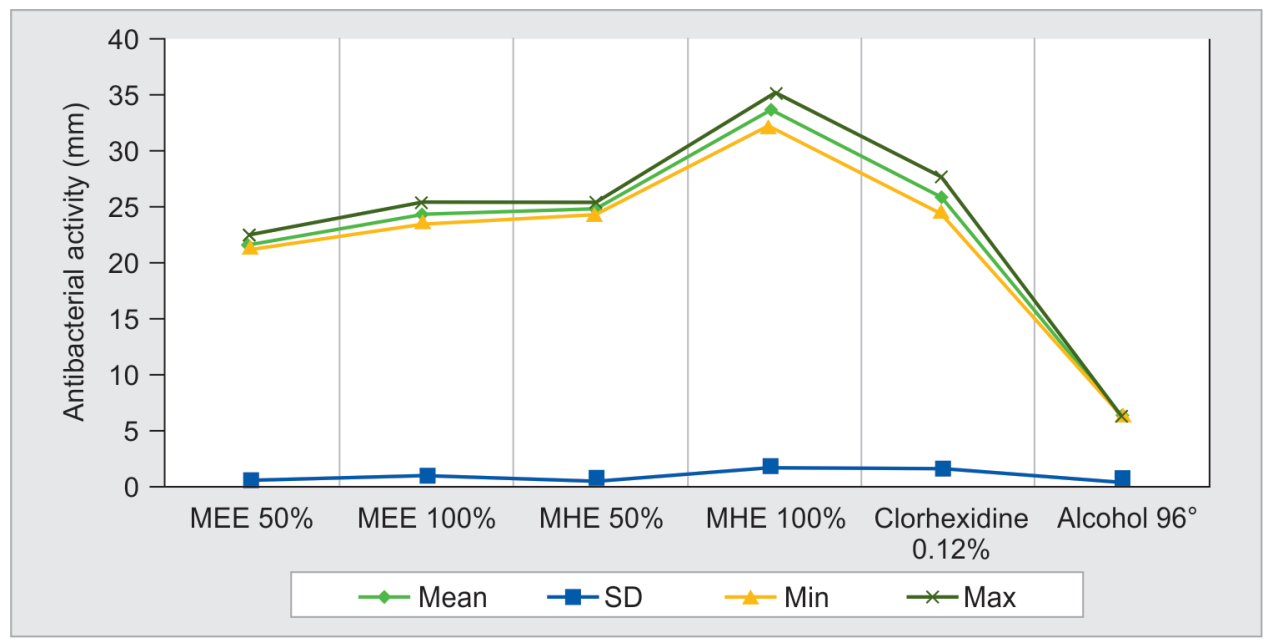

Fig. 3: In vitro comparison of Mangifera indica L. based ethanol and hydroalcoholic extracts 
so this effect could not be proven against other oral germs. In addition, the low availability of strains pure bacterial, limited this study. On the other hand, another limitation was the need to travel to the North of Peru to get this natural resource and transfer it to the capital (Lima), so time and logistics resources had to be invested to guarantee the correct transport of this plant to the microbiology laboratory.

The importance of this study is that it was verified that the leaves of the mango tree are found in large quantities in Northern Peru, and these have the ability to act as an antibacterial agent against a strain found in greater percentage in certain diseases such as osteomyelitis and other bacteremia. In addition, it had a methodological justification because it identified pharmacological effects and contributed scientific evidence to the profile of the mango plant on the S. aureus ATCC 6538 , so that it motivates the elaboration of subsequent investigations. Finally, this plant can be used as a possible alternative source for the production of new antibacterial agents of natural origin and accessible to the population.

\section{Conclusion}

It was determined that the ethanolic and hydroalcoholic extracts of the $50 \%$ and $100 \%$ mango leaves formed halos of inhibition at 24 hours against the strains of S. aureus ATCC 6538. In addition, when comparing the extracts, the $100 \%$ hydroalcoholic evidenced a halo of greater inhibition with statistically significant difference compared to the other concentrations of the extracts evaluated.

\section{ACKnowledgments}

We wish to thank to the Department of Microbiology of the Universidad Nacional Federico Villarreal. We also wish to thank to Universidad Científica del Sur for its constant support in the preparation of this scientific manuscript.

\section{References}

1. Medina D, Ulloa G, Camere R, et al. Antibacterial activity of Bixa orellana L. (achiote) against Streptococcus mutans and Streptococcus sanguinis. Asian Pac J Trop Biomed 2016;6(5):400-403. DOI: 10.1016/j. apjtb.2016.03.005.

2. Camere R, Ulloa G, Medina D, et al. Antibacterial activity of Myrciaria dubia (Camu camu) against Streptococcus mutans and Streptococcus sanguinis. Asian Pac J Trop Biomed 2016;6(9):740-744. DOI: 10.1016/j. apjtb.2016.07.008.

3. Mayta-Tovalino F, Gamboa E, Sanchez R, et al. Development and formulation of the experimental dentifrice based on Passiflora mollisima (Tumbo) with and without anion Fluor: antibacterial activity on seven antimicrobial strains. Int J Dent 2019;2019:9056590. DOI: 10.1155/2019/9056590.

4. Manzur AG, Sm Junior V, Morais-Costa F, et al. Extract of Mangifera indica $\mathrm{L}$. leaves may reduce biofilms of Staphylococcus spp. in stainless steel and teatcup rubbers. Food Sci Technol Int 2020;26(1):11-20. DOI: 10.1177/1082013219858529.

5. Shafiei Z, Rahim ZHA, Philip K, et al. Potential effects of Psidium sp., Mangifera sp., Mentha sp. and its mixture (PEM) in reducing bacterial populations in biofilms, adherence and acid production of S. sanguinis and S. mutans. Arch Oral Biol 2020;109:104554. DOI: 10.1016/j.archoralbio.2019.104554.

6. Ameen F, Srinivasan P, Selvankumar T, et al. Phytosynthesis of silver nanoparticles using Mangifera indica flower extract as bioreductant and their broad-spectrum antibacterial activity. Bioorg Chem 2019;88:102970. DOI: 10.1016/j.bioorg.2019.102970.

7. Chirayath RB, A AV, Jayakumar R, et al. Development of Mangifera indica leaf extract incorporated carbopol hydrogel and its antibacterial efficacy against Staphylococcus aureus. Colloids Surf B Biointerfaces 2019;178:377-384. DOI: 10.1016/j.colsurfb.2019.03.034.

8. Valdivia-Rivera S, Varela-Santos EDC, Quiñones-Muñoz TA, et al. Production of hydrocarbon-degrading microorganisms using agricultural residues of Mangifera indica $\mathrm{L}$. and Carica papaya as carbon source. 3 Biotech 2019;9(2):43. DOI: 10.1007/s13205-019-1574-2.

9. Bodiba DC, Prasad P, Srivastava A, et al. Antibacterial activity of Azadirachta indica, Pongamia pinnata, Psidium guajava, and Mangifera indica and their mechanism of action against Streptococcus mutans. Pharmacogn Mag 2018;14(53):76-80. DOI: 10.4103/pm.pm_102_17.

10. Subbiya A, Mahalakshmi K, Pushpangadan S, et al. Antibacterial efficacy of Mangifera indica L. kernel and Ocimum sanctum L. leaves against Enterococcus faecalis dentinal biofilm. J Conserv Dent 2013;16(5):454-457. DOI: 10.4103/0972-0707.117507.

11. Sundeep D, Vijaya Kumar T, Rao PSS, et al. Green synthesis and characterization of Ag nanoparticles from Mangifera indica leaves for dental restoration and antibacterial applications. Prog Biomater 2017;6(1-2):57-66. DOI: 10.1007/s40204-017-0067-9.

12. Shafiei Z, Haji Abdul Rahim Z, Philip K, et al. Antibacterial and antiadherence effects of a plant extract mixture (PEM) and its individual constituent extracts (Psidium sp., Mangifera sp., and Mentha sp.) on single- and dual-species biofilms. PeerJ 2016;4:e2519. DOI: 10.7717/ peerj.2519.

13. Singh R, Singh SK, Maharia RS, et al. Identification of new phytoconstituents and antimicrobial activity in stem bark of Mangifera indica (L.). J Pharm Biomed Anal 2015;105:150-155. DOI: 10.1016/j.jpba.2014.12.010.

14. Hannan A, Asghar S, Naeem T, et al. Antibacterial effect of mango (Mangifera indica Linn.) leaf extract against antibiotic sensitive and multi-drug resistant Salmonella typhi. PakJ Pharm Sci 2013;26(4):715-719.

15. Rajan $\mathrm{S}$, Thirunalasundari T, Jeeva $\mathrm{S}$. Anti-enteric bacterial activity and phytochemical analysis of the seed kernel extract of Mangifera indica Linnaeus against Shigella dysenteriae (Shiga, corrig.) Castellani and Chalmers. Asian Pac J Trop Med 2011;4(4):294-300. DOI: 10.1016/ S1995-7645(11)60089-8.

16. de Sousa Guedes JP, de Souza EL. Investigation of damage to Escherichia coli, Listeria monocytogenes and Salmonella enteritidis exposed to Mentha arvensis L. and M. piperita L. essential oils in pineapple and mango juice by flow cytometry. Food Microbiol 2018;76:564-571. DOI: 10.1016/j.fm.2017.09.020.

17. Poomanee W, Chaiyana W, Mueller M, et al. In vitro investigation of anti-acne properties of Mangifera indica $\mathrm{L}$. kernel extract and its mechanism of action against Propionibacterium acnes. Anaerobe 2018;52:64-74. DOI: 10.1016/j.anaerobe.2018.05.004.

18. Vimalraj S, Ashokkumar T, Saravanan S. Biogenic gold nanoparticles synthesis mediated by Mangifera indica seed aqueous extracts exhibits antibacterial, anticancer and anti-angiogenic properties. Biomed Pharmacother 2018;105:440-448. DOI: 10.1016/j.biopha.2018.05.151.

19. Ediriweera MK, Tennekoon KH, Samarakoon SR. A review on ethnopharmacological applications, pharmacological activities, and bioactive compounds of Mangifera indica (Mango). Evid Based Complement Alternat Med 2017;2017:6949835. DOI: 10.1155/2017/6949835.

20. Sundararaman B, Muthuramu KL. A comparison of mango seed kernel powder, mango leaf powder and Manilkara zapota seed powder for decolorization of methylene blue dye and antimicrobial activity. J Environ Biol 2016;37(6):1315-1321.

21. Madduluri S, Babu Rao K, Sitaram B. In vitro evaluation of antibacterial activity of five indigenous plants extract against five bacterial pathogens of human. Int J Pharm Pharm Sci 2013;5(4):679-684.

22. Diso S, Ali M, Mukhtar S, et al. Antibacterial activity and phytochemical screening of Mangifera indica (Mango) stem and leaf extracts on clinical isolates of methicillin resistant Staphylococcus aureus. J Adv Med Pharm 2017;13(1):1-6. DOI: 10.9734/JAMPS/2017/31127.

23. Anand G, Ravinanthan M, Basaviah $R$, et al. In vitro antimicrobial and cytotoxic effects of Anacardium occidentale and Mangifera indica in oral care. J Pharm Bioallied Sci 2015;7(1):69-74. DOI: 10.4103/09757406.148780 . 